\title{
A política linguística das universidades mexicanas depois da Covid-19
}

\author{
Language Policy in Mexican Universities after Covid-19 \\ Política lingüística de las universidades mexicanas después de la Covid-19
}

Recebido: 23/08/2021 | Revisado: 29/08/2021 | Aceito: 01/09/2021 | Publicado: 12/09/2021

\author{
David Guadalupe Toledo-Sarracino \\ ORCID: https://orcid.org/0000-0001-8795-2909 \\ Universidad Autónoma de Baja California, Mexico \\ E-mail: dtoledo@uabc.edu.mx \\ Laura Garcia-Landa \\ ORCID: https://orcid.org/0000-0001-7675-9644 \\ Universidad Nacional Autónoma de México, Mexico \\ E-mail: laura.garcia@enallt.unam.mx
}

\begin{abstract}
Resumo
O seguinte trabalho descreve as oportunidades e os desafios que enfrentam as universidades mexicanas que oferecem aulas de língua estrangeira durante a contingência sanitária da Covid-19. Este estudo quantitativo coletou informação a partir de um questionário dirigido aos diretivos dos departamentos de relações internacionais das universidades mexicanas incorporada à Associação Nacional de Universidades e Instituições de Educação Superior (ANUIES) no México. Os resultados traçam o futuro do ensino de línguas estrangeiras no país e as novas tarefas que se deve assumir no contexto educativo e a política linguística universitária, ademais de desenhar Cursos de Emergência Remota (CER), capacitação e novas formas de ensinar, além de dar seguimento ao bom funcionamento dos programas, o qual nos dá pautas para encaminhar os esforços à nova forma de ensinar com uma política linguística de acordo com a nova normalidade.

Palavras-chave: Educação superior; Política linguística; Covid-19; Ensino de línguas.
\end{abstract}

\begin{abstract}
The following paper describes the opportunities and challenges in Mexican universities that teach foreign languages face during the health contingency caused by Covid-19. This quantitative study gathered information from a survey sent to the heads of international affairs offices of Mexican universities affiliated to the National Association of Higher Education Institutions and Universities (ANUIES for its Spanish acronym) in Mexico. Results map the future of language teaching in the country and the new tasks to be taken within an educational context and university language policy, in addition to designing Online Emergency Courses (CER for its Spanish acronym,) training, and developing new ways to teach languages. Moreover, to follow up the good performance of some programs, which sets the standard to guide our efforts toward a new way of teaching with a language policy that fits this new normality.

Keywords: Higher education; Linguistic policy; Covid-19; Language teaching.

\section{Resumen}

El siguiente artículo describe las oportunidades y desafíos que enfrentan las universidades mexicanas que ofrecen clases de idiomas extranjeros durante la contingencia de salud Covid-19. Este estudio cuantitativo recogió información de un cuestionario dirigido a directores de los departamentos de relaciones internacionales de las universidades mexicanas, incorporados a la Asociación Nacional de Universidades e Instituciones de Educación Superior (ANUIES) en México. Los resultados perfilan el futuro de la enseñanza de lenguas extranjeras en el país y las nuevas tareas que deben emprenderse en el contexto educativo y política lingüística universitaria, además de diseñar Cursos de Emergencia Remota (CER), formación y nuevas formas de enseñanza, además de dar seguimiento al buen funcionamiento de los programas, lo que nos da pautas para orientar los esfuerzos hacia la nueva forma de enseñar con una política lingüística acorde con la nueva normalidad.
\end{abstract}

Palabras clave: Educación superior; Política lingüística; Covid-19; Enseñanza de lenguas. 


\section{Introdução}

No dia 31 de dezembro de 2019, a Organização Mundial da Saúde (OMS) comunicou ao mundo o novo surto da epidemia do Coronavírus (Covid-19) originado na província de Wuhan, China. Pouco tempo depois se informou a todas as nações que esta epidemia se converteu em uma pandemia que atingiu todas as nações do mundo.

A partir da propagação do vírus no mundo, foram desenhados protocolos e recomendações pelos especialistas em saúde que pediram a divulgação em todas as mídias, através de comunicados em meios oficiais e não oficiais recomendações para prevenir à comunidade e para não disseminar a doença, baseando-se nos protocolos da boa higiene de lavar as mãos, de cobrir a boca ao tossir, espirrar ou falar com o próximo e evitar o contato direto com qualquer pessoa. Isso resultou na decisão de um confinamento e/ou quarentena por mais de três meses a partir do surto nas localidades

O confinamento resultou no fechamento de dependências de serviço público, empresas, estabelecimento com atividades não essenciais tais como restaurantes, shoppings e casas noturnas, bares, museus e aeroportos. Somente ficando estabelecimento com atividades essenciais como o ramo médico, paramédicos, segurança e proteção cidadã, funcionamento da economia como supermercados, farmácia, postos de gasolina, lojas de serviços, mercearia, transporte, produção agrícola, produtos de limpeza, casa de material de construção, serviço de água potável, serviços postais, telecomunicações, agroindústria e indústria química (El Economista, 2020, p. 1).

As escolas, os centros escolares e as universidades tiveram que preparar o ajuste dos calendários escolares, sensibilizar seus estudantes para a nova modalidade de ensino e capacitar seus professores para ministrar aulas a distância, transitando da modalidade presencial para a modalidade virtual ou remota.

\section{A Covid-19 e a Educação Superior}

Diante dessa situação, tanto os webinars como a literatura publicada até o momento evidenciam a profunda iniquidade entre as zonas urbanas e rurais, assim como entre as classes sociais com respeito ao acesso à educação. O exposto aliado à existência de estruturas de Instituições de Educação Superior (IES) marcadas por uma crise cultural, social, política e econômica, que vê com grande preocupação a diminuição do seu orçamento como a Universidade Nacional Autônoma do México (UNAM) e o Instituto Politécnico Nacional (IPN); a redução da sua matrícula, como mostram algumas universidades privadas que não tem podido atender a demanda educativa online e inclusive, a ameaça de desaparecimento de certas universidades públicas devido à negação de um regaste financeiro, como a Universidade Autônoma do Estado de Morelos (UAEM) ou que vislumbrem seu declínio diante de um êxodo estudantil, no caso de universidades privadas com menos recursos. Podemos dizer que se trata de um problema complexo, multifatorial e necessariamente casuístico, já que os marcos de operações são diversos e correspondem às dinâmicas econômicas, sociais e culturais diferenciadas antes mesmo da pandemia, mas que se intensificaram com a sua chegada.

Dentro desde contexto de incerteza, uma nova relação espaço-tempo se abre, no sentido de que foi necessário modificar a relação entre o espaço público e o espaço privado. Faz-se alusão à sobreposição desses domínios e à confluências de situações e interações na mesma tela, tanto "de terno" quando de "chinelo" (Dussel, 2020). A linha tênue entre diferentes âmbitos e tempos "de casa", "de escola", "de trabalho" produz fadiga metal, tédio, ansiedade e depressão. O impacto dessa relação de tempo e espaço se traduz em uma 'série de circunstâncias que facilitam ou dificultam o acesso a uma educação de qualidade. Ao ficar em casa, os alunos podem ou não contar com as circunstâncias para trabalhar em casa, a distância: conexão à internet, número de equipamentos por membros da família, casos com Covid-19 na família, casos de violência intrafamiliar, aglomeração, desemprego. Por sua vez, os professores enfrentam desafios sem precedentes ao atender, de maneira simultânea, às aulas de línguas, as tarefas de casa dos seus 
próprios filhos e assistir as reuniões, entre a música do vizinho e os latidos do cachorro. O exposto anteriormente apresenta um panorama que exige uma grande flexibilidade e maturidade, responsabilidade, organização e desenvolvimento da autonomia, mas também novas normas de convivência no lar.

Em outros casos não será possível ao aluno trazer a escola para a casa e então, ao se ver desterrado de seu meio acadêmico, acabará abandonando os estudos, o que provoca o isolamento de suas redes, da comunicação com seus colegas e professores.

Além das populações em risco, existem também outras populações de estudantes que se tornaram vulneráveis à contingência devido à natureza do papel institucional que a internacionalização desempenha. Segundo a UNESCO (2020), a mobilidade internacional sofreu significativamente no período da pandemia. Quatro dos destinos mais procurados: Estados Unidos, Reino Unido, China e Austrália poderiam se encontrar em crise financeira, já que parte da matrícula corresponde a alunos de intercâmbio. O ponto anterior se deve às políticas de intercambio no marco da pandemia: restrição de viagem a determinados lugares, tanto para os docentes como para os alunos, fechamento de fronteiras, restrições epidemiológicas, condicionamento de vistos à gravidade que a pandemia apresenta em cada país, limitação de oferta de voos, questões financeiras (cancelamento de bolsas de estudo / falta de emprego dos pais). Previu-se que a restrição de mobilidade pioraria. Fala-se de um efeito de desglobalização caótica (UNESCO, 2020; TorresRivera, de San e da Silva, 2021). Surpreendentemente, e ao contrario deste fenômeno, está pendente a ratificação por vinte países da Convenção Mundial sobre o reconhecimento das qualificações relativas à Educação Superior pela Conferência Geral da UNESCO (25 de novembro de 2019). Este instrumento

... "estabelece princípios universais de reconhecimento de títulos através das fronteiras que facilitarão a mobilidade acadêmica dos estudantes, dos professores, pesquisadores e a aprendizagem no plano internacional, garantindo que as realizações acadêmicas sejam avaliadas e reconhecidas de forma equitativa com base de sólidos mecanismos de garantia de qualidade que permitem às pessoas continuar seus estudos e/ou buscar oportunidades de emprego no exterior (UNESCO, 2020, p. 25)."

$\mathrm{Na}$ mesma linha, espera-se que entrem em vigor as convenções regionais como a da América Latina e do Caribe (13 de julho de 2019), realizada em Buenos Aires, Argentina.

Esta política institucional está rachada por múltiplas questões mais urgentes no momento, quanto ao número de alunos e professores que enfrentam a situação de pandemia em um cenário de incerteza relacionando ao financiamento de seus estudos ou de estadias acadêmicas. Tanto alunos como professores e pesquisadores enfrentam agora a impossibilidade de contato para realizar suas atividades cotidianas em um intercâmbio: comunicação com acadêmicos e discentes no laboratório, no trabalho de campo, socialização no campus em uma língua e cultura estrangeira. O mesmo acontece com o intercambio cotidiano naquelas tarefas acadêmicas que não se podem fusionar o espaço de pesquisa na tela de sua casa.

A Covid-19 veio para mudar a formar de lecionar nas salas de aula de maneira presencial. Ao isolar alunos, professores e funcionários administrativos em casa, as universidades internacionais e nacionais tiveram que desenvolver planos de continuidade acadêmico em caso de desastres, pandemia e guerra. A contingência sanitária a nível global acelerou os processos de ensino nas universidades. Todas as universidades privadas e públicas pertencentes ou não aos rankings internacionais tiveram que gerar mecanismos de uma nova forma de instrução.

Pardo e Cobo (2020) apontam em seu estudo "Expandir la universidad más allá de la enseñanza remota de emergencia" que "Na pandemia, a prioridade das universidades tem sido a adaptação à situação de crise, garantindo pequenos sucessos permanentes de aprendizagem e sendo empáticos com a realidade socioemocional de suas comunidades (p. 5)”. 
A crise que se intensificou nas universidades projeta algo imprevisto. Algumas já tinham planos de contingência, outras não haviam pensado nisso. A Covid-19 veio a ser um divisor de águas na aceleração dos processos de fortalecimento da educação a distância iniciados nos anos 2000 e da nova cultura digital dos estudantes universitários. Gestores, administradores, professores e pesquisadores resistentes ao sistema de educação a distância foram obrigados a se atualizar com a nova modalidade de ensino nas universidades ou a se demitir por não se adaptarem. Em pouco tempo, saíram da sala de aula convencional para ministrar aulas, seminários ou workshops teóricos e práticos adaptados e estruturados nos formatos de plataformas educativas como Blackboard, Google Classroom, Moodle, Schoology, ArtCampus, Edmodo, etc. De mesma forma, aplicativos como Zoom, google meet, Zoom, Microsoft Teams Meetings, Skype y Webex Meetings têm servido como espaços digitais síncronos para a realização das aulas remotas. Atualmente, a educação a distância é uma realidade e no momento é uma das modalidades predominantes no ensino de línguas no ensino superior depois da Covid-19.

Embora essas plataformas existam, o confronto repentino com o coronateaching (ensino virtual em época da pandemia do Coronavírus), "um processo de transformação das aulas presenciais em um modo virtual, mas sem mudar o currículo ou a metodologia" nem a educação a distância emergencial, também levou a abertura e a flexibilidade sobre atividades remotas pouco aceitas pela academia. Ou seja, as universidades passaram a realizar atividades não planejadas anteriormente como as práticas profissionais remotas, atividades complementares ao serviço social, intercambio estudantil virtual, mobilidade acadêmica, participação em congressos virtuais, encontros com redes de pesquisa de maneira global, defesa de teses de graduação e pósgraduação, agilização dos processos administrativos tradicionais para processos mais eficientes.

Também se consolidou a promoção da aprendizagem de conteúdos disciplinares, competências digitais e de línguas estrangeiras online ou no Massive Online Open Course (em suas siglas em inglês MOOC) ministrados por prestigiosas universidades como Oxford, Havard, Exeter, Manchester, Michigan, Chicago, McGill, o Instituto de Tecnologia de Massachusetss (MIT) e a UNAM. No entanto, ainda existem algumas atividades que exigirão mais tempo para se adaptarem a esta realidade instável, em termos de distanciamento social, como a aplicação de exames de admissão e internacionais.

Essa realidade averta, contingente y mutável, cenário das IES em tempos de contingencia, torna necessária uma reflexão sobre a forma como a comunicação e a interação mudaram no curso do intercâmbio acadêmico, na geração de comunidades emergentes para a resolução dos problemas de saúde, social e ambiental, que têm tirado as universidades e os acadêmicos de sua atomização, para refletir sobre os valores sobre os valores humanos, a educação para a paz, a cultura da prevenção, a responsabilidade social, a construção de uma cidadania digital e o diálogo intercultural. Vejamos o caso específico das aulas universitárias de língua estrangeira. Como resultado dessas mudanças, questionamo-nos se existem políticas linguísticas emergentes que dão conta da nova forma de interação mediada pelas tecnologias e, em caso afirmativo, qual é a sua natureza. Nesta contribuição nos concentraremos no caso específico das aulas universitárias de línguas estrangeiras.

\section{A virtualidade das aulas universitárias de línguas estrangeiras}

Os centros de línguas dos campi universitários mudaram suas salas de aula físicas, blended ou a distância para o espaço virtual. Mas o espaço virtual da pandemia não é o mesmo que o espaço blended ou remoto, mas que coexiste com os espaços físicos dos ambientes que tanto professores como alunos habitam e que estão presentes ou incidem na natureza do espaço virtual. A verdade é que o espaço de cada participante está dividido entre diferentes espaços, tanto reais como virtuais de naturezas distintas e que podem ou não facilitar a aprendizagem e o ensino. Por exemplo, um professor no mesmo espaço físico atende a seu filho no ensino primário a distância, compartilha a sala de jantar com sua esposa que tem reuniões online com outros colegas de seu escritório e 
organiza os momentos para poder compartilhar equipamentos e recursos tecnológicos. Compreender a natureza desse espaço a partir de sua complexidade pode orientar as reflexões sobre o espaço virtual de forma mais clara, que não só inclui a parte tecnológica, mas também integra outros elementos. Um dos elementos que mudou é a relação entre tempo e espaço. A linha entre espaço e tempo promove a presença multidimensional ou à ubiquidade de alunos e professores. Diante dessa onipresença, existe também a multitarefa, composta por diferentes níveis: conexão rápida ou lenta à internet, eletricidade, gerenciamento de múltiplas plataformas e o trânsito entre elas em momentos distintos, o planejamento de aula, o e-mail, o Whatsapp, entre outros. Isso levanta problemas de atenção, de motivação, de estresse e até mesmo desgaste físico e mental.

Um segundo elemento a considerar é que embora exista este espaço-tempo físico, há também um espaço-tempo comunicativo que temos que estruturar e organizar, para que se desenvolva o trabalho em grupo, apoiado em um projeto de conhecimento que explore as possibilidades de pesquisar neste contexto particular da pandemia e que vincule toda a comunidade (Dussel, 2020, p. 15). Existem dois espaços específicos de comunicação no ensino superior, o síncrono e o assíncrono. O síncrono envolve uma interação virtual ao vivo, que permite a interação virtual em tempo real entre professores e alunos ou entre alunos. O espaço de comunicação assíncrona permite a interação em horários flexíveis e dá a oportunidade de uma interação mais pensativa, se fornecidas instruções para orientar a interação enriquecedora. Tanto nas universidades nacionais quanto nas internacionais, a solução tem se inclinado para o uso racional de ambas as formas de interação. Estudos relatados em webinars recentes indicam que a interação pode ser adaptada pelo professor, de acordo com suas necessidades específicas (Giordano et al., 2020; Prasetyono; Christian, 2020).

No que diz respeito ao trabalho em grupo e comunitário, a maioria dos educadores tanto universitários como de outros níveis educativos, consideram-no uma prioridade e as universidades, bem como outros níveis de ensino, estão explorando os melhores caminhos para realizá-lo, embora pareça essencial criar um clima de trabalho e colaboração neste espaço virtual, aliado a um espaço interior para o desenvolvimento das capacidades cognitivas ao nível individual (Clemens, 2020; Datta, 2020; García Llampallas, 2020; Jandette, 2020; Marginson, 2020; Souza \& Florencio da Silva, 2020; Oliveira, da Silva \& Pereira, 2021).

Um terceiro aspecto da virtualidade nas aulas de línguas é o tratamento do conteúdo para evitar longas horas de ensino de uma aula de línguas por videoconferência com Zoom. Algumas das experiências positivas vividas pelos professores são trabalhar no sequenciamento sistemático do conteúdo (Solares, 2020) e na seleção detalhada e adequada do input, a divisão do conteúdo na sala de aula invertida, "menos é mais" (García Llampallas, 2020).

O planejamento das aulas constitui um quarto aspecto da virtualidade. A experiência docente nas webinars indica que a definição de objetivos claros é essencial; bem como os alcances do curso, as metodologias que serão utilizadas para os atingi-los, e ainda a existência de indicadores de aproveitamento, que permitam ao aluno e ao professor refletir sobre a evolução da aprendizagem. Ter um planeamento geral de cada unidade didática em um sequenciamento didático pode facilitar o caminho (Kuklinski \& Cobo, 2020).

Um quinto aspecto é a elaboração de recursos didáticos. Este componente do espaço virtual exige estar atento aos elementos de planejamento: os objetivos, a metodologia, os indicadores de alcance, as plataformas adequadas para exibi-los, de acordo com o input que se deseja oferecer no recurso ou tipo de atividade que se tenha planejado. Se for aprendizagem colaborativa, aprendizagem por tarefas, por projetos; ou, o tipo de plataforma ou plataformas disponíveis na instituição ou que professores e alunos podem aderir para o funcionamento da aula: Google classroom, Moodle, blackboard, YouTube, Facebook, EdModo, Teams, Twitter; ou outras ferramentas disponíveis para torná-la mais dinâmica: Kahoot, Quizlet, Powtoon, Vocaroo, Voicethreath, Vold, Edupad, Cryptpad, Padlet, Jamboard, Mindmap, Mentimeter, Liveworksheets, Actionbound, Edpuzzle, Canva, Genially, ponderando a utilidade e adequação dessas ferramentas para os propósitos do curso. 
Para desenvolver esses recursos pedagógicos, o trabalho coletivo é muito enriquecedor, pois permite que professores do mesmo nível desenvolvam recursos para todos, tornando o tempo eficiente e, acima de tudo, retroalimentando sobre o desenho na prática (Torres-Rivera \& Silva, 2019; García Llampallas, 2020). É importante pensar, entretanto, que "aprender a usar ferramentas tecnológicas não qualifica o professor para a educação digital”. Requer um certo equilíbrio de variação, diferenciação e significado dos recursos com base na planeação. Consideramos o planejamento flexível a pedra angular e a base do desenho de recursos.

A avaliação no espaço virtual constitui um sexto componente da virtualidade no ensino de línguas. Três componentes essenciais mencionados por professores de línguas e educadores são proporcionar acompanhamento constante, retroalimentação e manter evidências compartilhadas de registros de avaliação nos quais o aluno e o professor possam ver o avance e que este exercício esteja integrado em seu processo em um exercício reflexão do aluno e retroalimentação do professor ao longo do curso. (Hirschfeld, 2020; García Llampallas, 2020).

Assim também, o processo avaliativo deve ser flexível, multimodal e colaborativo em mais de um nível. A flexibilidade se reflete em uma diversidade de atividades e formas de avaliação de caráter formativo, mais do que somativo, que dão conta do desempenho do aluno ao longo do curso: portfólios, sites, diários, infográficos, entre outros. Dentro dessa flexibilidade inclui também a multimodalidade: criação de um vídeo, projeto em grupo, reflexão individual, etc. A corresponsabilidade conforma uma parte central desse processo colaborativo, em que o professor solta o controle e até aceita formas de avaliação propostas pelo aluno e os sistemas de recompensa e sanção são negociados, favorecendo um clima de trabalho voltado para esse tipo de relação professoraluno, originada pela nova forma de ensino durante a pandemia (Hirschfeld, 2020; García Llampallas, 2020).

Outro aspecto a se considerar nesse processo é a relação professor-tecnologia, as tecnologias de informação e comunicação (TIC) durante a pandemia se tornaram na ferramenta básica do professor. Existe uma tensão em relação ao uso, associada ao acesso a equipamentos tecnológicos e aos serviços de telefonia e de internet nos diferentes contextos urbanos e rurais onde se desenvolvem tanto os alunos como os professores. Para alguns, o uso de novas plataformas acabou sendo um desafio e um benefício para a comunidade acadêmica global. Para outros, essa mudança gerou conflito e uma atividade de resistência. Em geral, o ensino online para alguns acabou sendo uma imposição. Para os professores que abraçaram a proposta enfrentam outros tipos de tensões, quanto à possibilidade de acesso dos alunos a essa modalidade de ensino, a gestão do tempo para preparar as aulas, e avaliar, a urgência de atualização nas dinâmicas e lógicas da educação online.

A formação de professores na modalidade virtual, portanto, torna-se uma prioridade, embora, devido às circunstâncias da pandemia no início, o professor foi derrubado em uma modalidade de ensino que não havia sido originalmente planejada desta forma e lhe produz alguma confusão. Ao mesmo tempo, os alunos enfrentam o fardo da aprendizagem autônoma nas costas, sem estar ainda preparados para isso, bem como as limitações técnicas para alunos e professores.

Em suma, é o que Kuklinski e Cobo (2020) chamam de ensino remoto emergencial. É uma solução temporária para um problema imediato, de alternativas temporárias para a entrega de conteúdo de um curso que não pode ser presencial, o que é de caráter obrigatório, uma vez que ninguém decidiu voluntariamente fazer um curso a distância, refere-se especificamente à distância espacial: distribuída, blended ou móvel. Geralmente, a educação online exige um planejamento meticuloso: planificação, desenho instrucional, determinação de objetivos a priori contextualizados em um ambiente virtual, o que não tem sido possível em todos os casos do ensino de línguas no ambiente universitário.

Algumas instituições universitárias optaram por adaptar os cursos presenciais a Cursos de Emergência Remota (CER) integrados por metas instrucionais, materiais destinados a medir as condições do corpo docente e o âmbito institucional com bibliografia online e o desenho de um método transitório do tradicional ao virtual sem deixar de lado as modalidades de avaliação 
do curso. O mesmo aconteceu com a nova forma do ensino de línguas estrangeiras nas universidades mexicanas. Devido às características próprias desses cursos, foi utilizada a estratégia "renove-se ou morra". Ou seja, para manter a elevada taxa de participação dos estudantes universitários, foram criados métodos próprios com ou sem o apoio de especialistas na área das TIC e do tratamento de línguas.

Outras instituições decidiram montar os seus cursos convencionais em diferentes plataformas educacionais ou optaram por contratar os serviços de editoras de prestígio que já desenvolvem os materiais adequados de aprendizagem de línguas estrangeiras, incluindo materiais do professor, livro do aluno, caderno de exercícios, acesso a sites associados aos cursos e sem deixar de lado a tutoria e os clubes de conversação em alguns casos.

Provavelmente, foi retomada a metodologia de aprender a aprender proposta por PINCAS (1985), a qual fomenta que os estudantes sejam responsáveis por sua própria aprendizagem (de maneira implícita e de forma autodidata em alguns casos. Isso resultou na geração de estratégias por parte dos professores para fortalecer as competências digitais e aprender conteúdos disciplinares. Em contrapartida, e conforme especificado acima, existe uma grande população estudantil que, embora tenham essas competências desenvolvidas, não possui as ferramentas e os equipamentos necessários para afiançar a sua aprendizagem na falta de equipamento informático, um telefone inteligente smartphone ou o acesso à Internet.

Apesar do período emergente do ensino de línguas a distância e das experiências positivas e negativas coletadas até agora, nos perguntamos o que acontecerá com essa sinergia uma vez que o "novo normal" seja retornado, de que maneira essa experiência a distância influenciará na forma de como a percebemos, dimensionamos, pensamos e agimos ao ensina línguas: questões de tipo logístico, questões de recursos pedagógicos, particularidades da incorpórea desta modalidade de ensino, a origem dos novos paradigmas de ensino, as inovações que dela originaram, as oportunidades de colaboração locais (entre alunos, professores e comunidade em geral), nacionais (entre universidades e outras entidades sociais, políticas e econômicas de um país) ou internacionais (entre universidades de vários países e organizações mundiais), como o programa da Universidade do Arizona, nos Estados Unidos, que marca uma ampla seletividade dos conhecimentos a adquirir, conforme a validação e relevância do conhecimento, desde uma perspectiva chamada microaprendizagem; ou bem, a relação igualitária e dialógica entre o Sul Global e o Norte Global para o enriquecimento mútuo, a formação de cidadãos globais conscientes do valor cultural de compartilhar ideias e conhecimento, de compartilhar e enriquecer através da diversidade linguística e cultural e a redução do seu impacto por não ter acesso suficiente aos serviços de internet.

Por outro lado, questionamo-nos como impactará esta situação à política educacional e linguística dos intercâmbios acadêmicos com outros países, como as bolsas Erasmus na União Europeia determinadas por uma política educacional que intensificava a cooperação acadêmica com modelos de inovação, mobilidade global, a preparação de aprendizagem de línguas na modalidade virtual e a incorporação das empresas nos novos modelos de ensino online (Reyes \& Vall-Llovera, 2012).

Embora tenham traçado alguns cenários possíveis para uma melhor educação em todo o mundo, as nações estavam preparadas para atender as situações de contingência sanitária. Isso significou que a Covid-19 chegou surpreendentemente ao mundo e de uma forma perturbadora paralisou e colapsou os sistemas econômico, político e educativo. Diante desses novos cenários de ensino na nova normalidade, requer-se de professores reflexivos e ávidos por repensar na universidade e nas novas formas de ensino.

\section{A política de línguas nas instituições de ensino superior}

O ensino de línguas nacionais e estrangeiras nas instituições de ensino superior segue obedecendo às políticas linguísticas de corte internacional (macroplanejamento) como de corte local (microplanejamento). A aprendizagem de mais de uma língua 
estrangeira pelo Banco Mundial e a promoção da diversidade linguística, ao da UNESCO, entram em tensão com os objetivos do planejamento linguístico na educação em instituições, particularmente no que diz respeito à mobilidade acadêmica e estudantil no marco da internacionalização, que se reduz a espaço bidimensional no marco da Covid-19.

Perguntamo-nos se existe algum tipo de questionamento em relação a essa política de linguagem tão presente no cenário da educação superior desde os anos 1990. Questionamo-nos se o ensino terá como foco o desenvolvimento de habilidades linguísticas relacionadas com o acadêmico ou se também se integrarão elementos de cunho sociopragmático (Leech, 1983) e sociocultural (Bravo, 2009) no intercâmbio através das redes sociais, um ensino que forme em padrões de interação distinta, adaptados a novas formas de interagir nos diferentes âmbitos, em que muda o co-texto (gestos) e o contexto (o extralinguístico como o vestuário).

Com o exposto anteriormente, poderia ter uma repercussão em todo o sistema de planejamento na educação, desde a formação docente, planos curriculares, desenho de recursos e materiais de ensino e aprendizagem, comunidade universitária e avaliação (Kaplan \& Baldauf, 1997, p. 124). Por isso, é necessário indagar se alguma rota de planejamento neste sentido é prefigurada e qual é a sua natureza.

\section{Metodologia}

Este estudo identifica se existe uma política emergente de línguas nas IES frente ao novo normal, derivado das novas formas de comunicação acadêmica, e, em caso afirmativo, qual é a sua natureza (Estrela, 2018). Também analisa as novas dinâmicas de comunicação no ensino de línguas e os novos cenários educativos enfrentados pelas IES, dar a conhecer o estado da política de internacionalização diante deste cenário, gera alguma abordagem geral para futuras pesquisas e visualiza alguns problemas específicos no planejamento linguístico.

Este trabalho exploratório coleta informação a partir de um questionário dirigido aos gestores dos departamentos de internacionalização das universidades mexicanas, membros da ANUIES, onde se averigua sobre as apreciações e os desafios que este campo de ação enfrenta durante a Covid- 19 em face do novo normal.

\section{Instrumento}

Foram entrevistados 30 gestores e funcionários das IES mexicanas através de um instrumento denominado Pesquisa sobre a política linguística das universidades mexicanas após Covid-19 (ver Anexo 1), com uma escala similar de descrições e alguns itens descritivos, integrados por novos itens, qualquer gráfico em uma matriz .xlsx para análise. A pesquisa tem 15 perguntas feitas nos formulários do Google e permite obter informação relacionada com a percepção dos diretores sobre a nova dinâmica de trabalho nos programas de língua estrangeira durante a pandemia.

Afirma-se que este instrumento foi validado pela consistência interna do instrumento sob o cálculo e interpretação de Alfa de Cronbach (1951) para o caso de validação interna. Ou seja, pela variância dos itens implementados no MS Excel com o pacote estatístico SPSS (22).

Para o cálculo de Alfa de Cronbach (1951)

$$
\alpha=[1-]
$$

Onde se indica o seguinte significado do cálculo:

$\alpha$ (Alfa de Cronbach)

K (Número de itens) 
V1 (Variância de cada item)

Vt (Variância total)

Indica-se que o resumo do processamento de casos e estatística de confiabilidade da pesquisa é a seguinte:

Tabela 1. Estatística de confiabilidade da pesquisa.

\begin{tabular}{|c|c|c|}
\hline & $\mathrm{V}$ & $\%$ \\
\hline Casos Válido & 30.00 & 100.00 \\
Excluído a & 0 & .0 \\
Total & 30.00 & 100 \\
\hline
\end{tabular}

Fonte: Autores (2021).

A eliminação por lista se baseia em todas as variáveis de procedimento.

Estatística de confiabilidade

Tabela 2. Estatística de confiabilidade da pesquisa.

\begin{tabular}{|c|c|}
\hline $\begin{array}{c}\text { Alfa de Cronbach baseada nos } \\
\text { elementos padronizados }\end{array}$ & No. de elementos \\
\hline .913 & 15 \\
\hline
\end{tabular}

Fonte: Autores (2021).

Com esses resultados de confiabilidade de Alfa de Cronbach (1951), confirma-se que o questionário é eficaz para fins de pesquisa. Menciona-se que as análises obtidas nos permitirão analisar o tratamento e as implicações da pandemia na política de línguas no ensino superior, especificamente nos programas de ensino de línguas estrangeiras ministrados nas universidades mexicanas.

\section{Resultados e Análises}

A partir da pesquisa denominada "Política de Linguística das Universidades Mexicanas depois da Covid-19" dirigida às IES pertencentes à ANUIES, foi alcançada a participação de 30 universidades de um universo de 180 IES participantes. Participaram universidades de Baja Califórnia, Campeche, Chiapas, Chihuahua, Cidade do México, Durango, Estado do México, Guanajuato, Guerrero, Hidalgo, Jalisco, Michoacán, Nuevo León, Morelos, Oaxaca, Puebla, Sinaloa, Veracruz e Zacatecas. Abaixo se mostra os resultados deste estudo na Figura 1:

Figura 1 - Plano de contingência na IES. 
1. Sua universidade teve um plano de contingência para atender a pandemia Covid-19?

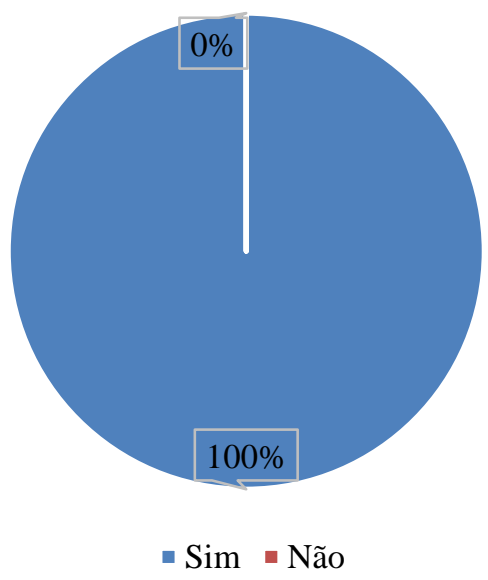

Fonte: Resultado do Questionário UABC (2021).

A Figura 1 mostra que 100\% das IES mexicanas pesquisadas apresentaram um plano de contingência acadêmica para atender as atividades relacionadas com a programação das aulas a partir de que o governo do México publicou no Diário Oficial da Federação (2020) o acordo que estabelece ações extraordinárias para atender a emergência sanitária gerada pelo vírus SARS-CoV2, que estabelece que as aulas presenciais em diferentes níveis de ensino não foram consideradas atividades essenciais.

Figura 2 - IES com programas de línguas estrangeiras online.

2. Sua universidade conta com a oferta acadêmica de cursos online para a aprendizagem de línguas estrangeiras?

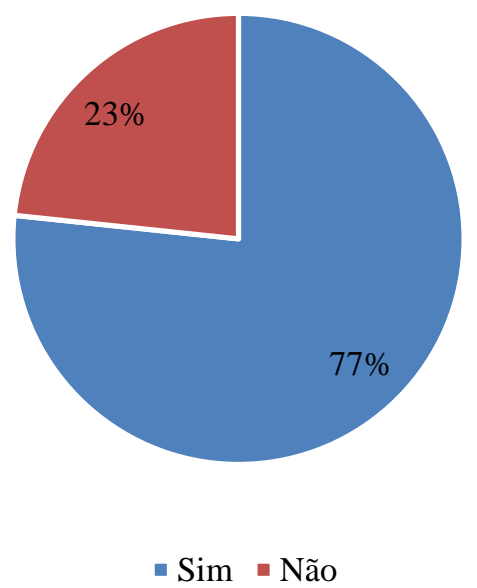

Fonte: Resultado do Questionário UABC (2021).

Na Figura 2, descreve-se que 77\% das universidades mexicanas tinham oferta acadêmica de ensino de línguas estrangeiras e $23 \%$ das instituições não continuaram com uma oferta acadêmica de cursos online. Ou seja, os cursos oferecidos foram transferidos 
para a modalidade não presencial. Menciona-se que 3\% das universidades não possuíam cursos online para essa atividade não convencional.

Figura 3 - Tipos de cursos.

3. Que tipo de cursos de línguas estrangeiras?

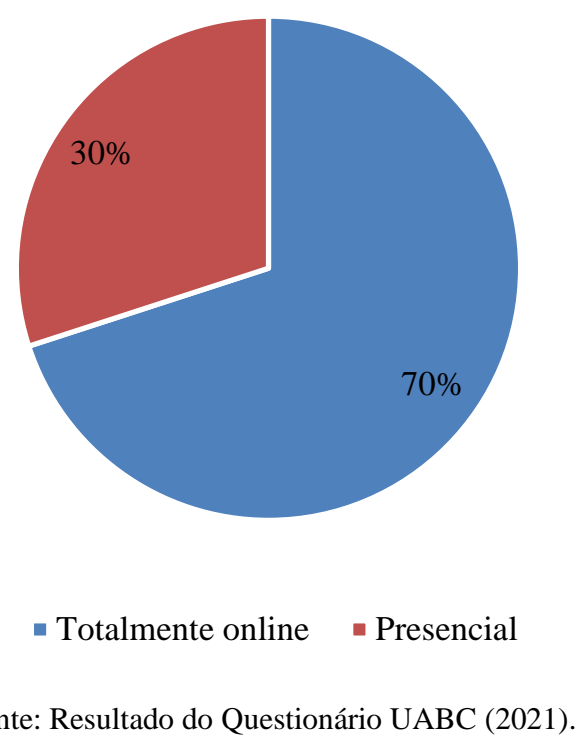

Na Figura 3, indica-se que 70\% das IES passaram para a modalidade totalmente online (visto que esta oferta não existia na universidade) e que $30 \%$ optaram pela continuação dos cursos na modalidade mista, atendendo os protocolos nacionais de saúde na adesão à dinâmica das aulas não convencionais. O que representou uma mudança drástica na metodologia de ensino de línguas estrangeiras. 
Figura 4 - Plataformas educativas utilizadas durante a contingência Covid-19.

4. Que tipo de plataforma virtual educativa utilizam para ensinar línguas estrangeiras?

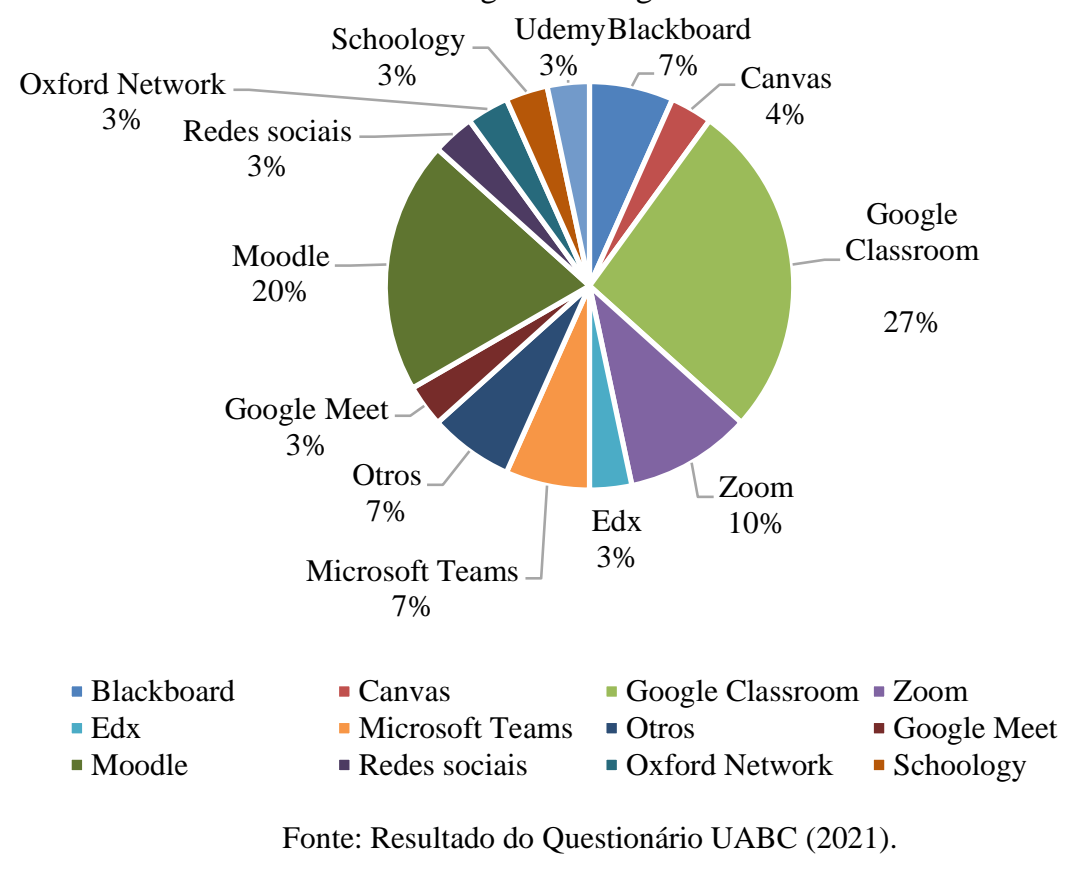

A Figura 4 mostra que as IES utilizaram uma ampla gama de plataformas digitais para o processo de incorporação em cursos a distância. Menciona-se que 27\% optaram pelo Google Classroom, 20\% pelo Moodle, 10\% pelo Zoom, 7\% pelo Microsoft Teams, 7\% pelo Blackboard, 4\% pelo Canvas e um conjunto de plataformas como UdeMy, Escolaridade. Rede Oxford, Redes Sociais, Google Meet e Edx, com 3\% cada, os 7\% restantes das IES pesquisadas ficaram com outras como WhatsApp, Messanger e e-mail.

Figura 5 - Capacitação docente.

5. Sua universidad ofereceu capacitação aos docentes sobre o uso das TIC e competencias digitais?

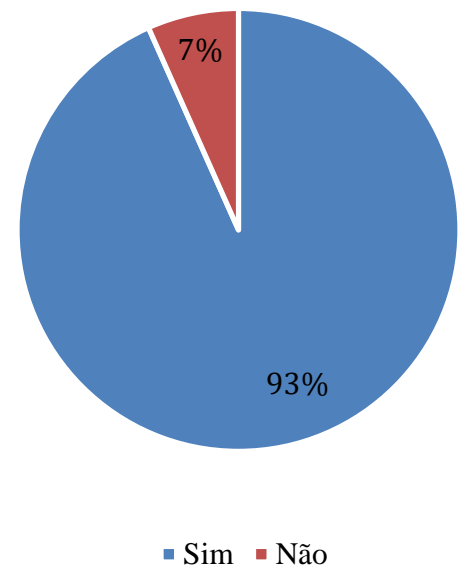

Fonte: Resultado do Questionário UABC (2021). 
A Figura 5 mostra com grande precisão que 93\% das IES pesquisadas realizaram um programa de formação docente para que os professores de línguas estrangeiras tivessem a atualização adequada para ministrar aulas na modalidade não convencional. $\mathrm{O}$ que significou uma mudança drástica para o tipo de ensino tradicional de aprendizagem de línguas estrangeiras.

Figura 6 - Aceitação dos cursos de capacitação e atualização.

6. O nível de aceitação dos cursos de capacitação e atualização ajudou os professores a melhorar sua prática docente.

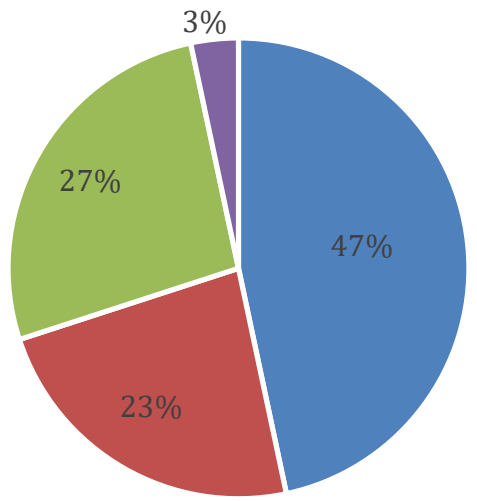

$$
\begin{array}{ll}
\text { - Concordo } & \text { - Nem concordo nem discordo } \\
\text { - Concordo totalmente } & \text { - Discordo totalmente }
\end{array}
$$

Fonte: Resultado do Questionário UABC (2021).

Na Figura 6 são descritos os indicadores relativos ao nível de aceitação dos professores à nova modalidade de ensino. 47\% indicam que concordam, $27 \%$ concordam totalmente, $23 \%$ não concordam nem discordam e $3 \%$ discordam totalmente. Um total de $26 \%$ estavam contra o tipo de capacitação docente que tiveram durante a pandemia. 
Figura 7 - Apoio para os alunos.

7. A instrução online apoiou para que os alunos melhorassem as competências linguísticas dos programas que se instruem na universidade.

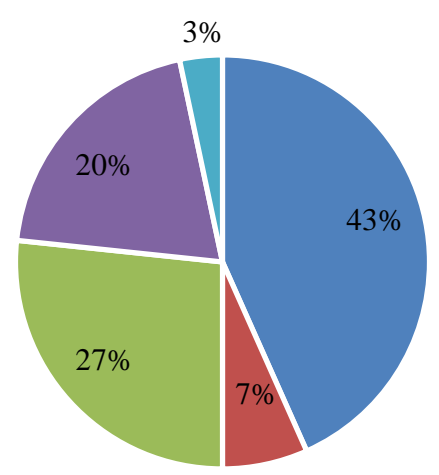

\footnotetext{
- Concordo

- Discordo

- Nem concordo nem discordo

- Concordo totalmente

- Discordo totalmente
}

Fonte: Resultado do Questionário UABC (2021).

A Figura 7 descreve o nível de aceitação dos professores em relação ao ensino online, pelo que se infere que os alunos aprimorarão as competências linguísticas em uma modalidade pouco explorada pelos centros de idiomas. Em si, 43\% concordam, $27 \%$ não concordam nem discordam, $20 \%$ concordam, $7 \%$ discordam e 3\% discordam totalmente. Em termos gerais, houve 10\% que não estavam favoráveis a essa nova modalidade. Supõe-se que há uma resistência a essa nova forma de ministrar os cursos e que, a partir dos resultados da pesquisa, pode-se deduzir que se trata de professores desatualizados ou relutantes em ministrar os cursos nas plataformas, 1) por desconhecerem a utilização dos plataformas 2) porque não foram capacitados 3) porque pertencem a uma geração apática às novas tecnologias e novas tendências do ensino de línguas estrangeiras sob uma modalidade não convencional. 
Figura 8 - Aprendizagem das competências linguísticas necessárias.

8. Com os cursos online os alunos adquirem as competências linguísticas necessárias.

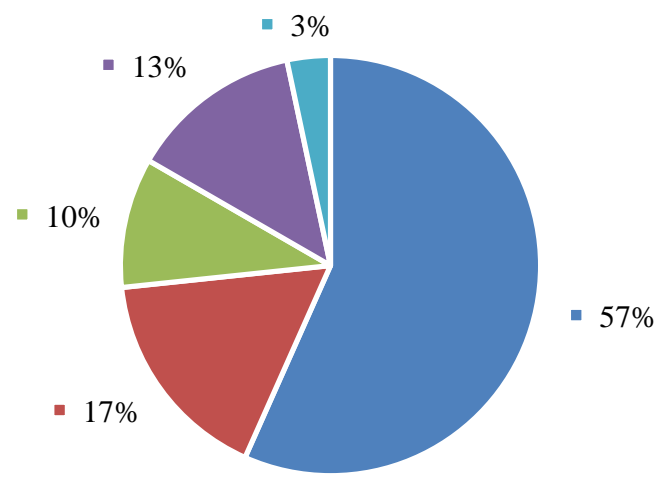

\footnotetext{
- Concordo $\quad$ - Discordo

- Nem concordo nem discordo - Concordo totalmente

- Discordo totalmente

Fonte: Resultado do Questionário UABC (2021).
}

Menciona-se na Figura 8 sobre o desenvolvimento das competências linguísticas que os alunos desenvolvem no processo de aprendizagem, comenta-se que, a partir da descrição dos gestores, 57\% concorda totalmente, 17\% discorda, 13\% concorda, 10\% não concorda nem discorda e 3\% discorda totalmente. Observa-se que há um melhor nível de aceitação, entretanto, 20\% indicam que não concordam nem concordam totalmente. Portanto, $80 \%$ estão mais sensibilizados à modalidade não convencional, pois o maior percentual da opinião dos gestores é de que há participação dos professores durante a pandemia para atingir os objetivos traçados durante o período escolar. 
Figura 9 - Mecanismos do ensino virtual.

9. Os mecanismos de ensino virtual desenvolvidos pela universidade são os adequados.

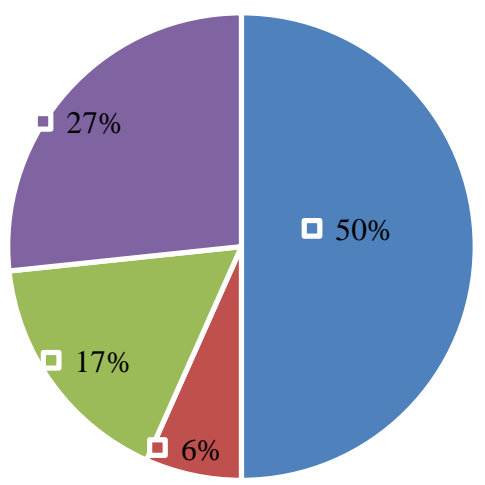

$$
\begin{aligned}
& \text { - Concordo } \quad \text { Discordo } \\
& \text { - Nem concordo nem discordo }=\text { Concordo totalmente }
\end{aligned}
$$

Fonte: Resultado do Questionário UABC (2021).

A Figura 9 descreve os mecanismos do ensino virtual desenvolvidos pela universidade, que de alguma forma foram executados a partir dos programas de ensino emergentes implementados pela IES. As opiniões dos gestores são variadas. 50\% concordam, $27 \%$ concordam totalmente, $17 \%$ não concordam nem discordam e 6\% discordam. Em termos gerais, o nível de aceitação dos mecanismos de ensino implementados pelas IES foi adequado com base na opinião dos gestores.

Figura 10 - Reuniões acadêmicas.

10. As reuniões acadêmicas permitiram valorizar pertinentemente os avances dos cursos online.

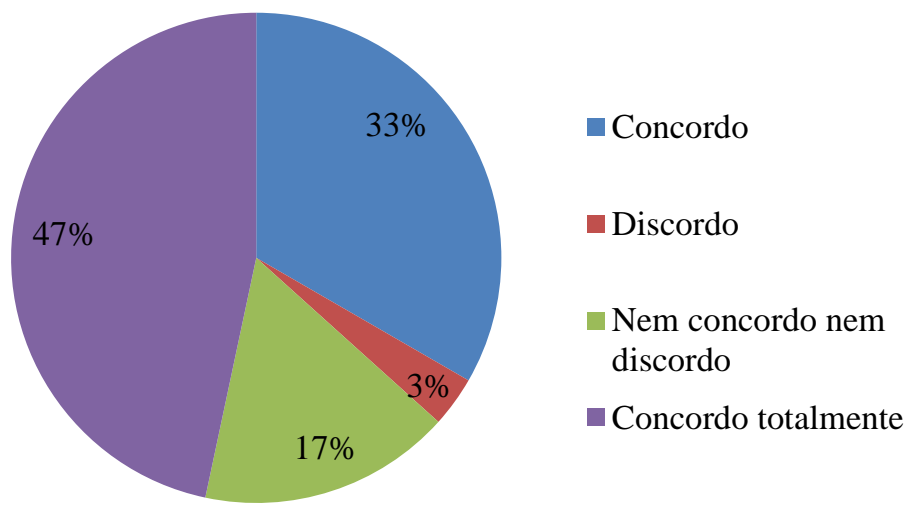

Fonte: Resultado do Questionário UABC (2021). 
Na Figura 10, as autoridades foram questionadas sobre o papel desempenhado pelas reuniões contínuas para avaliar a relevância dos cursos online nas IES. Dos entrevistados, $47 \%$ concordam totalmente, 33\% concordam, 17\% não concordam nem discordam e $3 \%$ discordam. Isso significa que $80 \%$ dos sondados se inclinam a favor de que as reuniões de acompanhamento acadêmico são efetivas eficazes e beneficiem o processo de aprendizagem das línguas estrangeiras.

Figura 11 - Regularização institucional.

11. Deveria haver alguma regularização institucional ou da comunidade docente que reja a interação entre docentes e alunos no contexto da educação a distância.

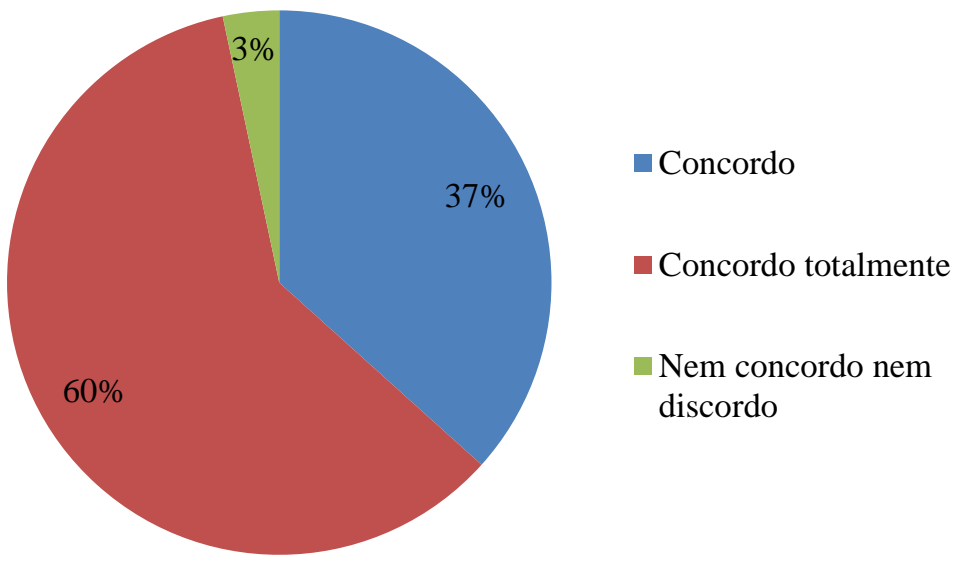

Fonte: Resultado do Questionário UABC (2021).

A Figura 11 descreve a possibilidade da existência de regulamentos ou diretrizes institucionais ou de academias na área de línguas estrangeiras que indiquem componentes claros sobre a educação a distância. Menciona-se que $60 \%$ concordam totalmente, $37 \%$ concordam e 3\% não concordam nem discordam. Infere-se que desde a incursão na modalidade não convencional, o corpo docente aderiu às diretrizes que foram estabelecidas nas IES para ministrar os cursos e atender a comunidade estudantil. Portanto, houve um alto nível de aceitação da maneira como professores e alunos interagem. 
Figura 12 - Critérios de avaliação.

12. Sería adequado desenhar critérios de avaliação pertinentes para os cursos online.

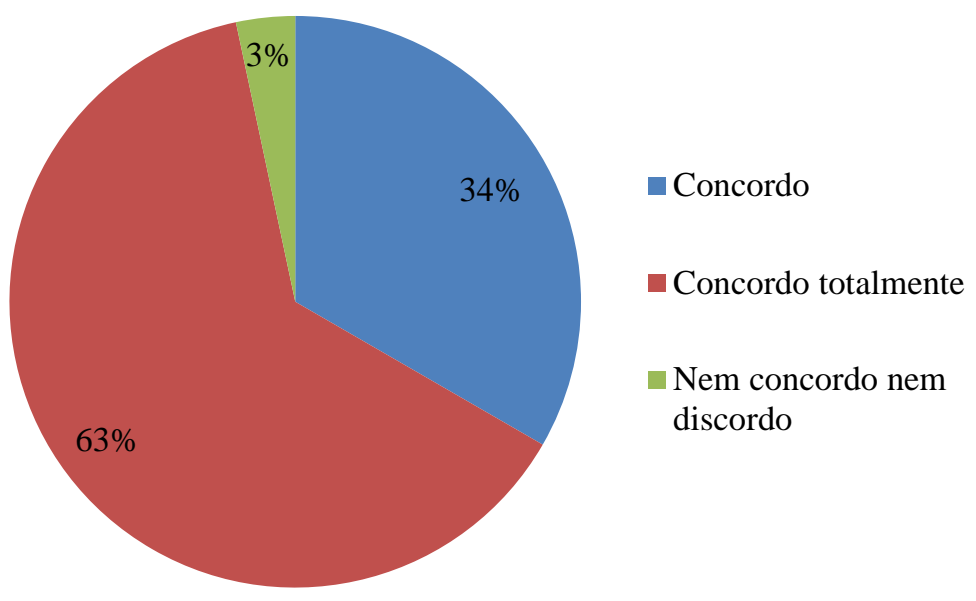

Fonte: Resultado do Questionário UABC (2021).

A Figura 12 descreve o indicador sobre os critérios desenhados para a realização dos cursos online. Comenta-se que $63 \%$ dos entrevistados concordam totalmente, $34 \%$ concordam e 3\% não concordam nem discordam. Portanto, observa-se que o maior número de participantes descreve que os critérios de avaliação seriam adequados desenhá-los nos planejamentos dos cursos e no esboço dos cursos online. O que representa que o sucesso dos cursos estará baseado no planejamento, implantação, desenvolvimento e avaliação dos cursos, apoiando da vida colegiada da instituição.

Figura 13 - Informação relacionada ao espaço virtual do ensino de línguas estrangeiras.

13. O espaço virtual do ensino de línguas permite o desenvolvimento de uma política linguística implícita.

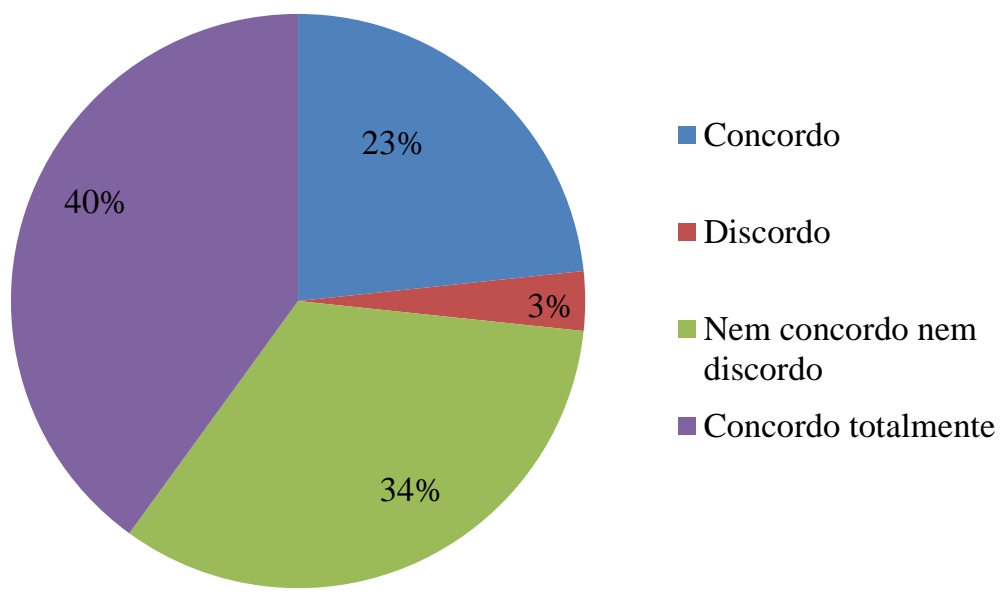

Fonte: Resultado do Questionário UABC (2021). 
Na Figura 13 são descritas as informações relacionadas ao espaço virtual do ensino de línguas estrangeiras, onde de maneira implícita ou explícita, a política linguística institucional de acordo com a opinião do dirigente ou gestor que de alguma forma atende os requisitos para o universitário continue se capacitando e aprendendo um idioma sob uma modalidade não convencional.

Conforme os resultados, $40 \%$ concordam totalmente, $34 \%$ não concordam nem discordam em que o espaço virtual permite um melhor desempenho da política linguística da instituição, $23 \%$ concordam e 3\% discordam. Portanto, é necessário pensar que a virtualidade de alguma maneira apoia as instituições para contar com um melhor desempenho nas tarefas de ensino.

Figura 14 - Política linguística da IES.

14. A política linguística de aquisição do Centro de Línguas deve coincidir com a política de internacionalização da instituição que pertence.

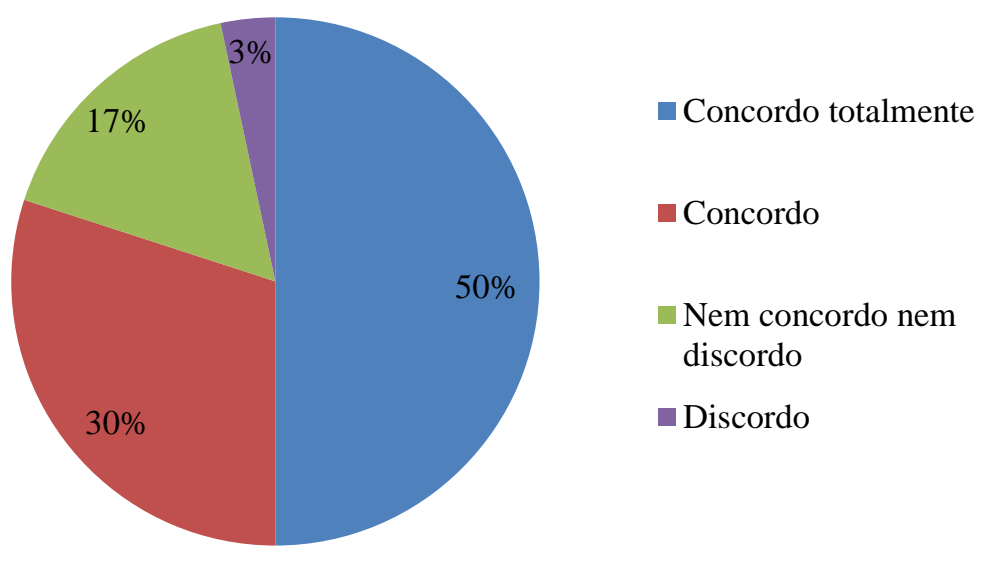

Fonte: Resultado do Questionário UABC (2021).

A Figura 14 descreve as informações coletadas sobre o planejamento linguístico na educação no Centro de Línguas, que deve coincidir com a política de internacionalização da IES. Com base nos resultados, $50 \%$ dos pesquisados indicam concordar com a forma como a política educacional está articulada à política de internacionalização. Refere-se que para a existência de internacionalização, as IES devem possuir programas educacionais em línguas estrangeiras que atendam às exigências dos organismos de acreditação, às demandas do setor de trabalho e à formação de competências globais que os alunos devem possuir ao se formar na universidade.

Por outro lado, $30 \%$ concordam, $17 \%$ não concordam nem discordam e finalmente 3\% discordam. É pertinente destacar que as IES devem ter programas de línguas estrangeiras de acordo com as exigências nacionais e internacionais. Dado que as IES mexicanas estão em processo de internacionalização, infere-se que não poderia haver política de internacionalização se as IES não ministrassem disciplinas que convidassem ao universitário a possuir competências linguísticas de acordo com as carreiras ministradas nas universidades 
Figura 15 - Apreciações sobre o futuro da LE após a Covid-19.

\section{Como considera que será o novo panorama de ensino de línguas nas universidades mexicanas depois da contingência sanitária da COVID-19?}

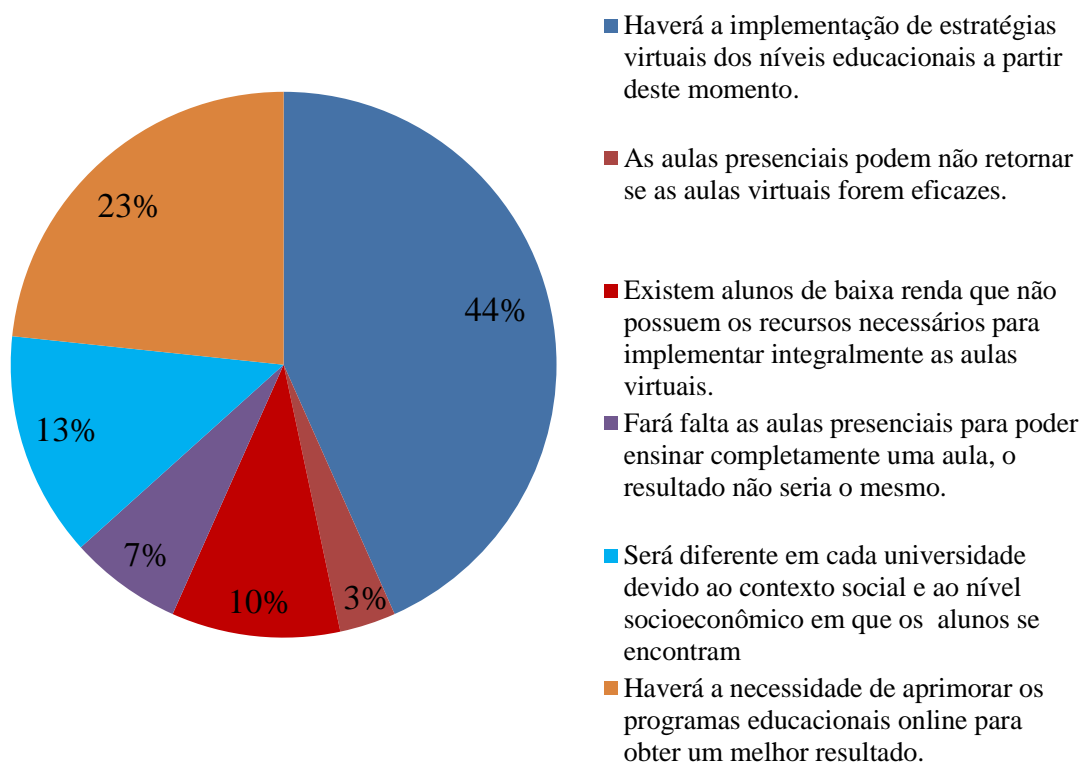

Fonte: Resultado do Questionário UABC (2021).

Na Figura 15 é feita uma descrição sintética dos comentários da questão aberta relacionada ao novo cenário do ensino de línguas estrangeiras após a Covid-19 e / ou no novo normal. Embora a pandemia tenha trazido mudanças significativas para as IES para a incorporação de novas formas de ensino, nesta questão $44 \%$ indicam que estabelecerão novas alternativas e implementação de estratégias de ensino em novos enfoques virtuais. Portanto, os entrevistados visualizam que os professores deveriam ser sensíveis às novas modalidades de ensino não convencionais para atender à política internacional das IES mexicanas.

Por outro lado, 23\% indicam que existe a necessidade de transitar para uma educação virtual coerente de acordo com as necessidades dos alunos e dos diferentes ambientes. O que significará que as IES devem investir na capacitação e formação docente nas TIC e em novas formas de ensino. Bem como todas as áreas de oportunidade necessárias para que os cursos de línguas sejam atrativos e funcionais.

13\% apontam que depois da pandemia será diferente e o ensino nos centros de línguas estrangeiras terá essa nova maneira de ensinar e implementar todas as novas tendências de aprendizagem de línguas. Por isso, é pertinente que as IES estejam atentas à nova forma de aprendizagem das línguas, uma vez que a interação social será o competente menos considerado neste novo panorama.

$10 \%$ apontam que ainda existe um hiato desigual diante daqueles alunos que não poderão se inscrever em cursos de língua estrangeira por falta de material (laptop, tablet, acesso à internet), o ensino se tornou mais exclusivo e elitista. Ou seja, as IES terão que promover novos mecanismos para que os alunos participem de programas semipresenciais ou totalmente a distância. O que representa uma alternativa à educação online. 
7\% indicam que após da Covid-19, as aulas presenciais usarão como atividades adicionais ou complementares todas aquelas atividades que desenvolvam as competências linguísticas com o uso da tecnologia; e 3\% tornaram-se menos encorajadores, argumentando que depois da Covid-19 nada mais será o mesmo e que será dificilmente voltará à forma como ensinávamos. Portanto, o novo normal será um componente a ser considerado na implementação de cursos de línguas estrangeiras.

Por fim, todas essas informações nos permitirão refletir sobre o futuro das línguas estrangeiras após da Covid-19 e quais serão as metas emergentes que as IES devem considerar, em um cenário real que represente a existência de mudanças significativas no novo normal e como abordá-las para continuar subsistindo.

\section{Discussão}

A grande questão é se podemos pensar sobre que tipo de política linguística emergirá ao passar pelo crisol da pandemia, com as características de uma crise geral estruturada (De Alba, 1998), desigualdade, incerteza, mudança nas relações entre os elementos da comunicação, especialmente de co-texto e contexto na competência sociopragmática (Leech, 1983) e sociocultural (Bravo, 2009), mediada agora pelo computador e, no caso da interação face a face, mediada pela face oculta atrás do símbolo da máscara e do face shield.

Até que ponto essa nova forma de comunicação nos impõe novas maneiras de perceber a imagem do outro, através da subtração do nível tridimensional de interação, quais são as marcas da pandemia e do ensino à distância de emergência (Solares, 2020) em a política da linguagem no ensino superior.

Em relação à forma de comunicação, em geral, não se percebe uma mudança substancial na política de línguas no ensino superior, exceto quanto à questão da adaptação do ensino de línguas para a modalidade online.

A linguagem não é dimensionada em um espaço de interação diferente do normalizado; isto é, o já conhecido. Mesmo aqueles que eram céticos apenas mencionaram que as competências linguísticas não são adquiridas nem desenvolvidas virtualmente. Nada foi mencionado sobre o contexto dos falantes, nem sobre os fatores linguísticos e extralinguísticos envolvidos na interação de nossos espaços virtuais na contingência e que estão influenciando de maneira importante na forma de se comunicar na vida cotidiana.

Localizamos quatro marcas da pandemia no que podemos identificar como uma política da linguagem do ensino superior emergente: 1) A produção coletiva de recursos de ensino; 2) consciência de novos tipos de avaliação; 3) A relação simbiótica entre a política educacional de internacionalização e a política da linguagem no ensino superior e 4) A formação de professores.

1. A produção coletiva de materiais didáticos é um dos pontos mais repetidos na necessidade de adequação dos recursos de ensino à nova modalidade online. Uma das instituições menciona a recuperação das melhores experiências de aprendizagem em sala de aula, por exemplo. Essa constatação coincide com (Clemens, 2020; Datta, 2020; García Llampallas, 2020; Jandette, 2020; Morgingson, 2020; Solares, 2020). Os aspectos mencionados pelos entrevistados destacam a desigualdade existente no acesso à educação online, bem como o contexto de incerteza e precariedade que prevalece em alguns dos domicílios; ou a impossibilidade de criar ambientes de aprendizagem na sala de aula virtual. Referem-se também à necessidade de "buscar elementos mais amplos de cooperação com instituições a distancia" para expandir o conhecimento cultural. Em suma, busca-se a colaboração para fortalecer práticas, diretrizes e mecanismos de ensino e avaliação de línguas na modalidade online.

2. A avaliação também obteve um lugar preponderante no interesse dos entrevistados. Fala-se em procurar os melhores instrumentos e modelos de avaliação, de acordo com a modalidade, mas também em procurar uma nova forma de ressignificar a avaliação, segundo as localidades, como expressam García Llampallas (2020), Nagao (2020) E Solares (2020) por meio de suas experiências como professores de línguas no ensino de alemão, japonês e inglês, respectivamente. 
3. A irrupção da pandemia na vida dos professores trouxe incertezas e, para alguns, uma tensão entre a tradição e a modernidade. Os docentes vivenciaram a transição para a sala de aula virtual como uma "mudança abrupta" que requer tempo e recursos "para que melhores condições sejam proporcionadas no processo, bem como acompanhamento para que as aulas sejam um espaço de ensino confortável, seguro e com suficiente motivação.” Não é suficiente bom dar aulas de chinelos. Como sugere Dussel (2020), há uma realidade mais profunda e complexa relacionada às condições de trabalho do professor neste novo espaço-tempo, que exige uma consciência da dimensão humana, reflexiva e crítica do ensino, para além da mera transmissão de conhecimentos linguísticos.

4. Por fim, um quarto ponto diz respeito ao vínculo entre a política educacional que coloca no centro a internacionalização das IES e a política da linguagem que possibilita ou não a concretização dessa política. Os participantes da pesquisa se mostram positivos referente a que possam continuar a mobilidade estudantil e acadêmica em tempos de pandemia e depois dela. Não se discute as implicações que possa ter o fato da não mobilidade no ensino de línguas, particularmente do enfoque com fins académicos; ou nas novas formas de interação social, por meio das redes sociais, nem da possível convivência face a face em termos do distanciamento social. O que se menciona em apenas um caso é a importância de promover a língua inglesa pelo escopo de suas funções sociais em termos de planejamento de status: desenvolvimento de aplicações, geração de artigos acadêmicos internacionais e contato com estudantes estrangeiros para intercâmbio de conhecimento.

\section{Conclusões}

Voltando ao objetivo central deste estudo: identificar se existe uma política emergente de linguagem nas IES frente ao novo normal, derivada das novas formas de comunicação acadêmica, e em caso afirmativo, qual é a sua natureza. Identificamos que ainda não foi desenvolvida uma política linguística emergente explícita para a comunicação mediada pela tecnologia. No entanto, os participantes deste estudo mencionaram alguns elementos que indicam uma política linguística implícita.

No que diz respeito à análise das novas dinâmicas de comunicação no ensino de línguas e dos novos cenários educacionais enfrentados pelas IES, detectamos que:

a) Alguns problemas específicos foram identificados no planejamento linguístico (ver discussão)

b) Propostas específicas foram geradas sobre as futuras pesquisas a respeito do ensino de línguas estrangeiras, a Covid-19 e a era pós-pandêmica.

c) Quanto à geração de uma política de linguagem explícita; por exemplo, nas questões de gênero que, embora não constassem nos dados, temos ouvido falar de casos de professores que foram desligados de suas funções por esse motivo.

d) Em relação à sociopragmática da sala de aula, que novas chaves temos para ler os rostos e os corpos das pessoas interagindo por trás de uma máscara e uma face shield (escudo de plástico) na interação face a face mediada pelo computador em um funeral, em uma reunião familiar, em um cyber café, em uma missa, etc.

e) No que se refere à política de internacionalização, as IES têm gerado esquemas de mobilidade acadêmica virtual e intercâmbio estudantil virtual com base na limitação de poder se locomover para atender aos indicadores institucionais. No entanto, a experiência cultural e linguística não será a mesma por meio de um monitor que estando no país da universidade de destino.

f) Borrou-se a presença da combinação de áreas específicas como a política e o planejamento linguístico e as TIC para a elaboração de Cursos Emergentes Remotos, porém seria necessário refletir sobre os resultados que foram obtidos para o bom funcionamento dos programas e se os universitários obtêm as mesmas competências linguísticas em uma sala de aula virtual. 
O exposto nos permite refletir sobre as tarefas que as universidades mexicanas devem assumir durante e após a pandemia tal como aponta Boaventura de Souza (2020), que a pandemia e as quarentenas que os vivem os indivíduos mostram alternativas de vida e as diferentes sociedades as quais devem se adaptar à nova normalidade e aos novos estilos de vida quando necessário e que haja um bem comum. Isso significa que a universidade deve repensar uma nova forma de ensinar com novas alternativas para viver, produzir, consumir e conviver em uma nova sociedade pós-pandêmica. Ao que se acrescentaria uma nova abordagem para pensar nas novas formas de ensino e manter os padrões de qualidade sem comprometer a produtividade e a saúde física e mental de professores e alunos.

O ensino de línguas no México se consolidou nas últimas quatro décadas, prova disso é que os centros de línguas apoiam os processos de internacionalização da universidade com os indicadores de formar alunos com conhecimento linguístico e pensamento global. De fato, aprender línguas estrangeiras é visto como um processo complexo no novo normal, pois implica ensinar com uma metodologia adequada, formar com uma boa concepção da língua, contar com programas com estratégias didáticas e metodológicas adequadas que levem os alunos a desenvolverem habilidades sociais, competências linguísticas, sociopragmáticas, culturais e digitais. Sem dúvida, caberá aos tomadores de decisão repensar e reformular os modelos de ensino tradicionais para um ensino em sintonia com as tensões globais. Sem dúvida, as línguas estrangeiras são requisitos essenciais para a cooperação acadêmica e a vinculação da universidade com o exterior; portanto, mais atenção deve ser dada ao seu desenvolvimento.

Por fim, ter um planejamento estratégico poderá atender as políticas educacionais nacionais, que devem ser congruentes com o setor produtivo e também reforçar uma política linguística emergente que surja a partir de eventos inesperados (pandemias, catástrofes, guerras, greves) que revolucionaram o mundo e que as instituições educacionais devem superá-los e encontrar soluções imediatas como apontado por Boaventura de Souza (2020) de dar respostas com um novo senso comum, a ideia simples e óbvia de que, especialmente nos últimos quarenta anos (p. 31). Sem dúvida, o ensino de línguas deverá sofrer mudanças significativas para se reinventar e evoluir.

Após a realização deste estudo, afirma-se que a vida acadêmica sofreu mudanças significativas na pandemia de Covid-19 para aprimorar as práticas de cultura digital e aprendizagem de línguas. Assim, o ensino de línguas estrangeiras (nas diferentes modalidades de ensino) proporcionará como resultado possível estudos sobre as melhores práticas pedagógicas que irão influenciar os bons resultados dos espaços educativos de ensino das línguas estrangeiras e das políticas linguísticas na universidade. o contexto será modificado e abrirá novas reflexões e novos campos de estudo pouco explorados, como o ensino de línguas em modalidades não convencionais, o uso de novas plataformas, novas formas de formar professores e realizar pesquisas. Sem dúvida, este estudo fornece as reflexões necessárias para motivar os especialistas em línguas para novas modalidades de ensino e direcionar novas pesquisas sobre a funcionalidade dos cursos remotos de emergência (CER) que surgirão nas universidades públicas mexicanas após o Covid-19.

\section{Referencias}

Boaventura de Sousa, S. (2020). La cruel pedagogía del virus. Traducción de Paula Vasile. Buenos Aires: Consejo Latinoamericano de Ciencias Sociales (CLACSO). Bravo, D. (2009) Pragmática, sociopragmática y pragmática sociocultural. Una introducción. En: Bravo, D., Hernández, N. F., Cordisco, A. (Ed.). Aportes pragmáticos, sociopragmáticos y socioculturales a los estudios de la cortesía en español. Buenos Aires: Dunken.

Clemens, C. (2020). Online Teaching Boot Camp: Best Practices for Language Instructors. Primera jornada de buenas practices. Escuela Nacional de Lenguas, Lingüística y Traducción, UNAM. https://www.youtube.com/watch?v=gIXg3gI3acs\&t=104s.

Datta, R. (2020). Digital Transformation of Higher Education and the Future of Online Teaching and Learning. En Reimagining \& Transforming the University: Confluence of Ideas During and Beyond Covid -19, https://www.facebook.com/JindalGlobalUNI/videos/reimagining-transforming-the-university-confluence-ofideas-during-and-beyond-co/716332649148293/. 
De Alba, A. (1998). Currículum. Crisis, mito y perspectivas. Miño y Dávila eds.

Diario Oficial de la Federación. (2020) Acuerdo por el que se establecen acciones extraordinarias para atender la emergencia sanitaria generada por el virus SARSCoV2. Recuperado de: https://www.dof.gob.mx/nota_detalle.php?codigo=5590914\&fecha=31/03/2020\&print=true.

Dussel, I. (2020). La clase en pantuflas: Conversatorio virtual con Inés

Dussel. https://www.youtube.com/watch?feature=youtu.be \&v=6xKvCtBC3Vs\&app=desktop

El Economista. (2020) ¿Cuáles son las actividades esenciales que no pararán en la contingencia del Covid.19?. https://www.eleconomista.com.mx/politica/Cualesson-las-actividades-esenciales-que-no-pararan-en-la-contingencia-del-Covid-19-20200331-0061.html.

Estrela, C. (2018). Metodología Científica:Ciencia, Ensino, Pesquisa. Editores Artes Médicas.

García Llampallas, C.G. (2020). Aula invertida: ¿cómo planear tu clase a distancia? Segundo webinario de buenas prácticas docentes. Escuela Nacional de Lenguas, Lingüística y Traducción - UNAM. https://www.youtube.com/watch?v=gIXg3gI3acs\&t=104s.

Giordano, L., Cipollaro, L., Migliorini, F., \& Maffulli, N. (2020). Impact of Covid-19 on undergraduate and residency training. The Surgeon. https://doi.org/10.1016/j.surge.2020.09.014

Hirschfeld, D. (2020). Primera jornada de buenas prácticas. Escuela Nacional de Lenguas, Lingüística y Traducción - UNAM. https://www.youtube.com/watch?v=gIXg3gI3acs\&t=104s.

Jandette, J. (2020). La motivación del aprendiente en modalidades no presenciales. Primera jornada de buenas prácticas. Escuela Nacional de Lenguas, Lingüística y Traducción, UNAM. https://enallt.unam.mx/img/actividades/1JornadaBP.pdf.

Kaplan, R. \& Baldauf, D. J. (1997) Language Planning form Practice to Theory. Multilingual Matters.

Kuklinski, H. P. \& Cobo, C. (2020). Expandir la universidad más allá de la enseñanza remota de emergencia. Ideas hacia un modelo híbrido post-pandemia. Barcelona: Outliers School.

Leech, G. N. (1983). Principles of Pragmatics. Longman.

Marginson, S. (2020). Global Virtue Conference Jindal Global University. Challenges and Possibilities. En Reimagining \& Transforming the University: Confluence of Ideas During and Beyond Covid -19. https://www.facebook.com/JindalGlobalUNI/videos/reimagining-transforming-the-university-confluence-of-ideas-duringand-beyond-co/716332649148293.

Nagao, K. (2020). Transformación de las prácticas didáctica en contextos en línea: Herramientas / materiales. Primera jornada de buenas prácticas. Escuela Nacional de Lenguas, Lingüística y Traducción, UNAM. https://www.youtube.com/watch?v=gIXg3gI3acs\&t=104s.

Oliveira, H. F. M., da Silva, R. F., \& Pereira, V. A. (2021). Modos de aprender em tempos de pandemia: Deficiências e importância da inclusão digital para alunos da rede pública. Research, Society and Development, 10(7), e53410716610-e53410716610.

Organização Mundial da Saúde - OMS. (2020). Coronavirus, 2020. https://www.who.int/es/health-topics/coronavirus.

Organização Mundial da Saúde - OMS. (2020). Brote de enfermedad por Coronavirus (Covid-19, 2020. https://www.who.int/es/emergencies/diseases/novelcoronavirus-2019.

Pardo, K., \& Cobo, C. (2020). Expandir la universidad más allá de la enseñanza remota de emergencia Ideas hacia un modelo híbrido post-pandemia. Barcelona: Outliers School.

Pincas, A. (1985). Writing in English. MacMillan.

Prasetyono, T. O. H., \& Christian, A. (2020). Multiscreen to screen webinar for education beyond border: A review. Annals of Medicine and Surgery, 59, $237-241$.

Programa de las Naciones Unidas para el Desarrollo - PNUD. (2020). Desarrollo Humano y Covid-19 en México. Desafío para una recuperación Sostenible. PNUD.

Reyes, S. \& Vall-Llovera, M. L. (2012). Las experiencias educativas de movilidad virtual de los estudiantes de formación de posgrado: Un estudio del caso UNAB OUC.

Solares, M. E (2020). Más allá de la Enseñanza Remota de Emergencia. Cursos intersemestrales Escuela Nacional de Lenguas, Lingüística y Traducción, UNAM. https://www.youtube.com/watch?v=nqXf7XTX1JM.

Sousa, O. C. \& Florencio da Silva, R. Contributions of Technology to Distance Learning. How the University will need to reinvent itself to face the challenges of the 21st Century. Revista ESPACIOS, 41 (02).

Torres-Rivera, A. D., \& Silva, R. F. D. (2019). Aprender a convivir en Educación Superior desde la Práctica Docente, para una Sociedad Democrática. Formación universitaria, 12(2), 51-62.

Torres-Rivera, A. D., de San, J. A. S. R., \& da Silva, R. F. (2021). Innovación Social Y Políticas Públicas Territoriales Sustentables: Comunidades De OaxacaMexico. Revista Brasileira de Gestão e Desenvolvimento Regional, 17(2).

UNESCO. (2020). Covid-19 y educación superior: De los efectos inmediatos al día después. Análisis de impactos, respuestas políticas y recomendaciones. http://www.iesalc.unesco.org/wp-content/uploads/2020/05/COVID-19-ES-130520.pdf. 


\section{UNIVERSIDADE AUTÔNOMA DE BAJA CALIFORNIA \\ PESQUISA SOBRE A POLÍTICA LINGUÍSTICA DAS UNIVERSIDADES MEXICANAS DEPOIS DA COVID-19.}

Nome da Instituição Localidade

Instruções: Ler cuidadosamente e responder a seguinte informação:

O objetivo desta pesquisa é coletar informação relacionada com as ações vinculadas às tarefas que as universidades mexicanas realizam em relação ao tema de ensino de línguas estrangeiras. Este instrumento faz parte do estudo denominado "A política linguística das universidades mexicanas após Covid-19", que ajudará a compreender sobre as problemáticas enfrentadas pelos centros de línguas durante a contingência sanitária.

1. Sua universidade teve um plano de contingência para atender a pandemia Covid-19?

Sim__ Não

2. Sua universidade conta com a oferta acadêmica de cursos online para a aprendizagem de línguas estrangeiras?

Sim__ Não

3. Que tipo de cursos de línguas estrangeiras?

Presencial __ semipresencial __ Totalmente online __ Nenhum

4. Que tipo de plataforma virtual educativa utilizam para ensinar línguas estrangeiras?

Blackboard___ Moodle____Schoology__Udemy___ Outra_

5. Sua universidade ofereceu capacitação aos docentes sobre o uso das TIC e competências digitais?

Sim__ Não

6. O nível de aceitação dos cursos de capacitação e atualização ajudou os professores a melhorar sua prática docente.

Concordo totalmente __ Discordo__ Não concordo nem discordo__ Concordo__

7. A instrução online ajudou os alunos a melhorar as competências linguísticas dos programas ministrados na universidade.

Concordo totalmente _ Discordo__ Não concordo nem discordo__ Concordo__

8. Com os cursos online os alunos adquirem as competências linguísticas necessárias.

Concordo totalmente _ Discordo__ Não concordo nem discordo__ Concordo__

9. Os mecanismos de ensino virtual desenvolvidos pela universidade são os adequados.

Concordo totalmente _ Discordo__ Não concordo nem discordo__ Concordo_

10. As reuniões acadêmicas permitiram valorizar pertinentemente os avances dos cursos online.

Concordo totalmente _ Discordo__ Não concordo nem discordo__ Concordo__

11. Deveria haver alguma regularização institucional ou da comunidade docente que reja a interação entre docentes e alunos no contexto da educação a distância. Concordo totalmente _ Discordo__ Não concordo nem discordo__ Concordo__

12. Sería adequado desenhar critérios de avaliação pertinentes para os cursos online.

Concordo totalmente __ Discordo__ Não concordo nem discordo__ Concordo__

13. O espaço virtual do ensino de línguas permite o desenvolvimento de uma política linguística implícita.

Concordo totalmente _ Discordo__ Não concordo nem discordo__ Concordo__

14. A política linguística de aquisição do Centro de Línguas deve coincidir com a política de internacionalização da instituição que pertence.

Concordo totalmente _ Discordo__ Não concordo nem discordo__ Concordo_

15. Como considera que será o novo panorama de ensino de línguas nas universidades mexicanas depois da contingência sanitária da Covid-19? 